\title{
Religious circumcision on the NHS: opinions of Pakistani people in Middlesbrough, England
}

\author{
Raj Bhopal, Rajan Madhok, Aqueela Hameed
}

\section{Department of Epidemiology and Public Health, University of Newcastle upon Tyne R Bhopal R Madhok \\ Tees Health Authority, Middlesbrough \\ A Hameed \\ Correspondence to: Professor R S Bhopal, Department of Epidemiology and Public Health, The Medical School, Newcastle upon Tyne, NE2 $4 \mathrm{HH}$. \\ Accepted for publication 24 April 1998}

\begin{abstract}
Meeting the health needs of ethnic minority populations requires understanding their culture and adapting services appropriately. ${ }^{1}$ The medical benefits of routine male circumcision are controversial, both in medical and ethical terms, with tangible though rare dangers and possible benefits. ${ }^{23}$ Routine male circumcision for cultural and religious reasons ${ }^{2}$ is vexing professionals, parents, and decision makers in Britain and North America. ${ }^{3-5}$ In Britain there is no national policy on the role of the NHS in routine circumcision though a new project aims to provide guidance. ${ }^{6}$ The General Medical Council's guidance (September 1997) acknowledged conflicting views that cannot be resolved by doctors and the GMC, and emphasised that doctors should listen to and respect patients' views.

People from Pakistan are Britain's third largest ethnic minority group ${ }^{1}$ and their major religion, Islam, advocates male circumcision (in the expectation of health benefits), so their opinion is important. We report such opinion from Middlesbrough, England, where the local health authority does not purchase services for non-medical circumcision (which are available privately from a local general practitioner).
\end{abstract}

Table 1 Opinion on the importance of male circumcision being available on the NHS, by personal and social characteristics (Figures are percentages rounded to nearest integer with the number in parentheses)

\begin{tabular}{|c|c|c|c|c|}
\hline & \multicolumn{4}{|c|}{$\begin{array}{l}\text { Response to question: How important do you feel it is for male } \\
\text { circumcision to be provided on the NHS? }\end{array}$} \\
\hline & Very important & Important & $\begin{array}{l}\text { Not very } \\
\text { important or } \\
\text { not important }\end{array}$ & No opinion \\
\hline All $(n=126)$ & $53(67)$ & $30(37)$ & $6(7)$ & $12(15)$ \\
\hline \multicolumn{5}{|l|}{ Sex } \\
\hline Men $(n=63)$ & $71(45)$ & $24(15)$ & $2(1)$ & $3(2)$ \\
\hline Women $(n=63)$ & $35(22)$ & $35(22)$ & $8(5)$ & $22(14)$ \\
\hline \multicolumn{5}{|l|}{ Birthplace } \\
\hline UK $(n=40)$ & $55(22)$ & $20(8)$ & $5(2)$ & $20(8)$ \\
\hline Pakistan $(n=83)$ & $52(43)$ & $34(28)$ & $8(5)$ & $6(7)$ \\
\hline \multicolumn{5}{|l|}{ Age group } \\
\hline$<25(n=40)$ & $45(18)$ & $28(11)$ & $3(1)$ & $25(10)$ \\
\hline $25-44(n=62)$ & $60(37)$ & $21(19)$ & $6(4)$ & $3(2)$ \\
\hline 45 or more $(n=24)$ & $50(12)$ & $30(7)$ & $8(2)$ & $13(3)$ \\
\hline \multicolumn{5}{|l|}{ Car ownership } \\
\hline Own a car $(\mathrm{n}=64)$ & $61(39)$ & $27(17)$ & $8(5)$ & $5(3)$ \\
\hline Do not own a car $(\mathrm{n}=62)$ & $45(28)$ & $32(20)$ & $3(2)$ & $19(12)$ \\
\hline \multicolumn{5}{|l|}{ Income $(f)$} \\
\hline$<10000(\mathrm{n}=44)$ & $50(22)$ & $36(16)$ & $2(1)$ & $11(5)$ \\
\hline$\geqslant 10000(\mathrm{n}=55)$ & $53(29)$ & $25(14)$ & $11(6)$ & $11(6)$ \\
\hline \multicolumn{5}{|l|}{ Ward code } \\
\hline Most prosperous $(n=42)$ & $60(25)$ & $19(8)$ & $14(6)$ & $7(3)$ \\
\hline Middle group $(n=42)$ & $50(21)$ & $33(14)$ & $2(1)$ & $14(6)$ \\
\hline Least prosperous $(n=42)$ & $50(21)$ & $36(15)$ & $0(0)$ & $14(6)$ \\
\hline
\end{tabular}

\section{Methods and results}

In 1991 Middlesbrough had 3646 Pakistani residents $(2.6 \%$ of the population). Most had origins in the Mirpur area in Punjab, Pakistan, and were speakers of the Mirpuri Punjabi dialect. Our aim was a sample representing a mix of ages and socioeconomic circumstances, to be identified by the Pakistani name from the electoral register. There was no validated list of such names, so identification was based on our knowledge. The general approach has been tested. $^{78}$ At interview, only two potential subjects were not Pakistanis. For practical reasons relating to identifying subjects, four electoral wards containing 10 or fewer Pakistani were excluded. The remaining 21 wards were arranged in three categories (most, less, and least prosperous) using four economic variables of car ownership, unemployment, home ownership, and overcrowding in the Townsend index. The electoral registers of all seven wards in the most prosperous category and a sample of three wards from each of the other two categories were name searched.

The date of birth and sex of people identified from the electoral register were taken from the family health services authority register. Our target sample size was 126 . An equal number (21 males and 21 females from the three age bands $18-29,30-44$, and 45-64 years) were chosen randomly from each of the three groups of wards. No more than one person per household was selected.

Our questionnaire included the question "How important do you feel it is for male circumcision to be provided on the NHS?" The words "...on the NHS" echo both colloquial use and the phraseology of discussions within NHS management. The subjects were interviewed at their homes in summer 1993 by two Pakistani interviewers fluent in Punjabi, Urdu, and English who were trained by the third author and by a professional interpreter and translator.

The initial response rate was $85.7 \%$ (108 of 126). Five people declined to be interviewed, two were not Pakistani, one had died, and others were unavailable. The 18 non-respondents were replaced by the next name on the appropriate list (all participated). There were 63 men and 63 women. Table 1 shows that respondents thought it important that the NHS provide male circumcision. 


\section{Discussion}

In a climate of financial constraint and emphasis on clinical and cost effectiveness, circumcision is, rightly, undergoing scrutiny..$^{2-5}$ National guidance has emphasised that decisions should be made locally after consultation. Our data show that the provision of circumcision services on the NHS is important to those affected by it. Elsewhere, the public has been willing to pay for such a service provided by NHS Trusts. ${ }^{6}$ Before deciding that routine circumcision is not a matter for the NHS, decision makers serving Pakistani communities should note these findings, and ascertain local opinion.

We thank the subjects for participating, Nusrat Hussain for help with training the interviewers, Parveen and Yaqub Mughal for interviewing, Sandra Green for help with analysis and Tees Health Authority for financing the study.
Conflicts of interest: none.

1 NHS Executive. Ethnicity and health in England. London: HMSO, 1995.

2 Wallerstein E. Circumcision: ritual surgery or surgical rite? Med Law 1983;2:85-7.

3 General Medical Council. Guidance for doctors who are asked to circumcise male children. London: General Medical Council, 1997.

4 LeBourdais E. Circumcision is no longer a "routine" surgical procedure. Can Med Assoc f 1995;152:1873-6.

5 Ciesielski-Carlucci C, Milliken N, Cohen N. Determinants of decision making for circumcision. Camb Q Healthc Ethics 1996:5:228-36.

6 Page S. Meeting demand. NHS Magazine 1997;9:15.

7 Nicoll A, Bassett K, Ulijasyek SJ. What's in a name? Accuracy of using surnames and forenames in ascribing Asian ethnic origin. F Epidemiol Community Health 1986;40: 364-8.

8 Colman AJ, Braun T, Gallagher RP. The classification of ethnic status using name information. $\mathcal{F}$ Epidemiol Community Health 1988;42:390-5. 